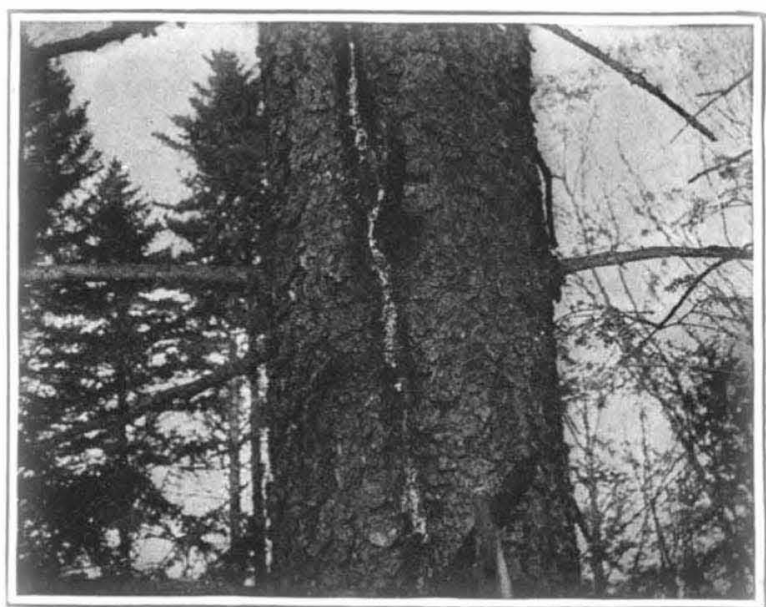

A frost crack, showing the spruce gum

NE of the minor industries of the North Woods is the gathering of spruce gum. It furnishes regula employment to a hundred men and is casually engaged in by several hundred others. It is in Maine that this industry is at its best and there every year some 15,000 tons of crude gum, valued at a third of a million dollars, is harrested. There are two gum diggers or pickers, of whom the writer has personal knowedge, who bring who bring out of the woo pounds of lump gum and from six to eight tons of scrape. The value of each man's gleanings is between $\$ 1,500$ and $\$ 2,000$ a year.

Crude gum is formed as the result of injury to red and black spruce trees. Hedgehogs feed upon the inner bark of the trees and the injuries they cause, known as " ho cuts" are fruitful sources of gum. Iightnin as "hog cuts," brasions caused by falling trees, and even sap sucker drills are other occasions for gum formation. Around the edges of such wounds little nodules appear and gradually develop into lumps or teats. A wide scar heals slowly and ma produce gum around the entire wounded area, while a narrow seam closes so quickly that only a single row of these "nugrets" is possible At first these are mere the mouth and are of unpleasant taste. It requires at least five years to transform this material into the hard and brittle amber-like gum. If it remains on the tree too long spruce gum deteriorates and becomes very dark colored.

The stimulation of the gum by artificial means is not practiced. Very recently, however, some experiments to this end have been started by Mr. V. C. Isola of North Newry, Maine. Four different methods have been used, namely, rossing the bark from portions about a foot square near the base of the tree, similar to the work of porcupines; removing a strip of bark 2 inches wide and from 15 to 20 feet long from the south side of a tree to imitate the scar made by another tree in falling; splitting the bark for a vertical distance of 20 feet to give the effect of a frost crack; removing two parallel strips of bark and leaving a two-inch strip between them.

Preceding these experiments study was made of the factors affecting the production of gum. It was noted that the sunny side of a tree is more productive than the shady, that trees on exposed ridges yield more tha

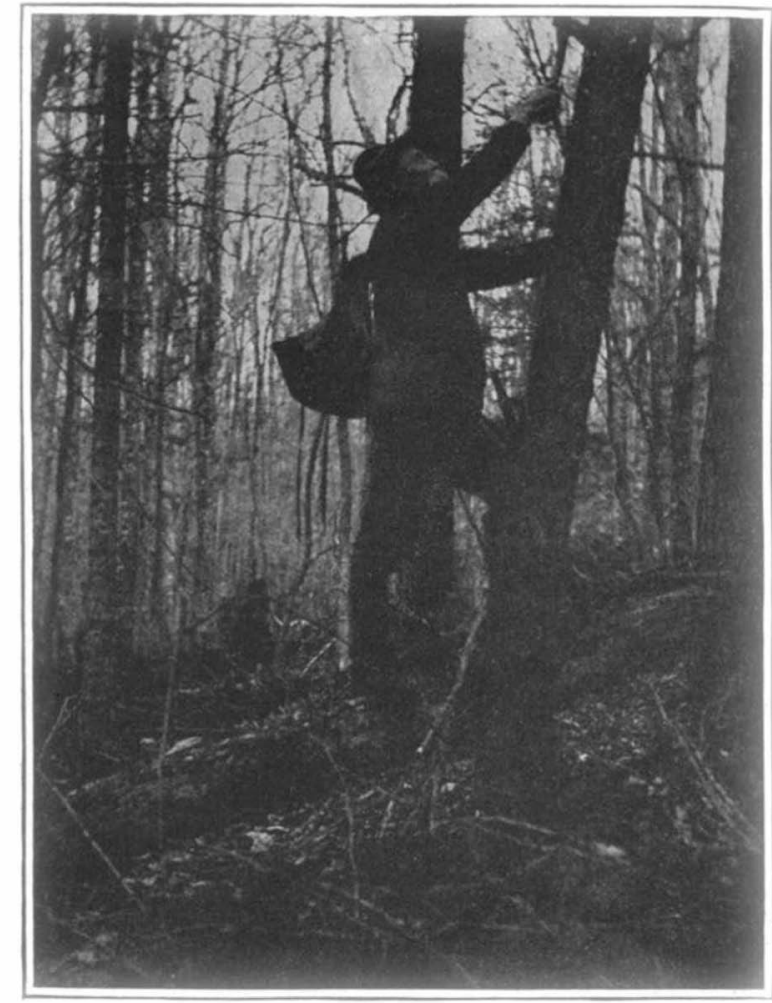

A sprace gummer busy at his daily tagk

\section{The Spruce Gum Industry}

An Important Article of Commerce from the Northern Woods

By Samuel J. Record

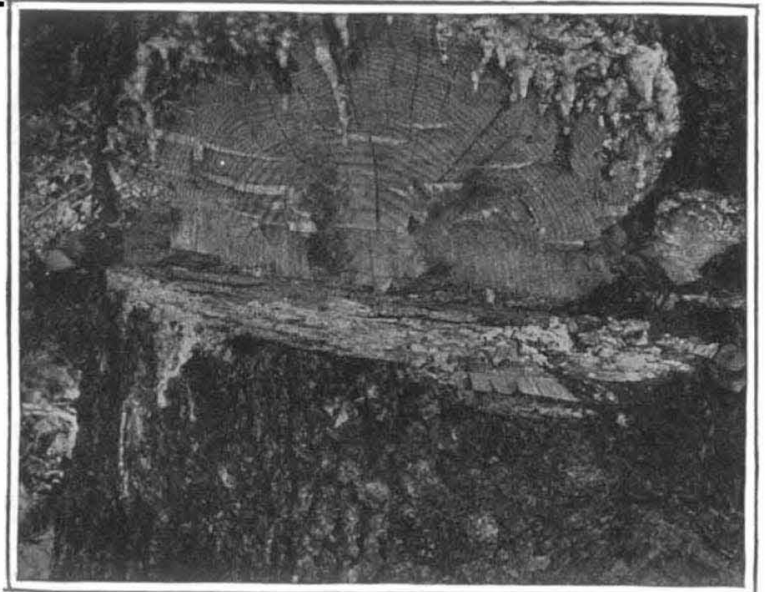

Under cut on a spruce tree, showing the pitch exudation

those in cover and on protected slopes, and that the best gumming is usually found in mixed stands of spruce hemlock and hardwoods, and not in pure spruce stands. An exception to this was found in the case of ledg slopes where porcupines were numerous. Weather conditions probably play some part, as yet unknown, in the formation and ripening of the gum.

Gum gathering is confined to the virgin forests as the Field of cut-over tracts and second-growth stands is too meagre to pay. A territory once gummed is ready for a second gumming in from five to seven years. The gatherers work alone, in pairs, or sometimes in partie of three or four. Working just ahead of logging operations has many advantages in the matter of transporta-

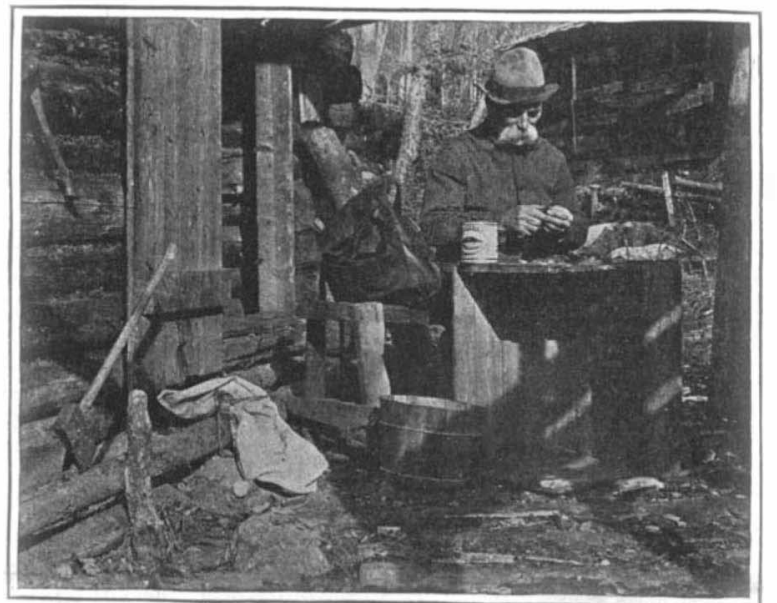

The spruce gummer cleaning gum at the door of his shack

tion both of food supplies and of the gum. A little log hut near the scene of operations affords better shelter than a tent in cold weather, though the tent has the advantage of being readily moved. Gumming and trapping are often combined.

Gathering gum proceeds the year around, though the best time is when the leaves are off the bushes and undergrowth, thus facilitating travel and making the gum easier to "spot." At such times, too, the fiies are absent or less of a pest. Going is best in March whe the deep snow covering the underbrush is crusted over. The gum in cold weather is extremely brittle and often files into fragments when touched with the ax or gathering tool. These would be lost in soft snow, but are easily recovered from the crust. Walking in the deep snow the picker is able to find and reach many choice bits of gum which otherwise might pass unnoticed. Not all of the gum is high up in the tree. In fact a great deal of it occurs near the base and considerable quantities are picked up from the ground where it had fallen after being broken off by the swaying of the tree in the wind, by frost action, or other means. During the snow season this part of the crop is inaccessible.

In gathering the gum the men work systematically n strips three to four rods wide. Where the gum is within easy reach the gatherer holds a bag or his hat under it and chips it off with a small ax. For higher up the tree he may build a staging, climb the tree, or in exceptional cases cut the tree down. Some operators use a special gathering tool, a chisel (usually made from an old file) inserted in the end of a pole and a tin receptacle fastened just beneath the chisel. The other end of the handle is hollowed out so that a stick can be fitted into it for extension. This enables the collecting of lumps far out of reach otherwise, though so much breakage of the gum results that many profesionals will not use such tools.

Work in the woods begins at daybreak and is usually concluded by 3 P.M. Upon returning to camp the collector goes over the contents of his back pack and sorts and cleans it. Rainy days may also be devoted to this purpose. So far as possible all bark and other foreign. material is removed and the lump gum is put away carefully in a cool, safe place. In warm weather the lumps are put in a bag and sunk in a brook or spring to prevent the pieces sticking together. The scrapings and crumbs are stored in a barrel.

The yield of a day's work varies considerably. Some pickers consider 25 to 30 pounds a fair day's toll while others claim to average as high as 40 pounds, and some thes make 00 pouds. Gett chip gum out of the woon is quite a task, particularly when far from hand sled or toboggan and drawn out by hand.

Crude spruce gum is divided into two principal grades, lump and chip. Lump gum, as the name implies, comprises the nuggets or "tits" as they are known in the vernacular of the trade. This material may be separated into three grades based largely upon color and weight, which are mainly matters of age. First grade is light in weight, porous, and about the color of good honey. It is quite free from moss, bark and other impurities when gathered. The wholesale price for this grade is quite stable at from $\$ 2.25$ to $\$ 2.50$ a pound. Second grade is reddish or wine-colored and is not so porous as first grade, though for chewing purposes it may be fully as good or better. The difference in color and consistercy is due to this gum being a little older. Third grade is a catch-all for lump gum that will not go into the first two grades. It is old gum that has usually begun to deteriorate and varies widely in color, being often quite dark. It sells for about $\$ 1.50$ a pound wholesale. It is sometimes put up in small half-ounce pasteboard boxes which retail for five cents each.

Chip gum contains the scrape from wounds on the tree, and the crumbs and fine particles resulting from cleaning lump gum. This material is so full of foreign matter that it has to be refined before going on the market. It is first washed in three or four changes of water and the free bits of spruce bark, fine moss, and dirt rise to the surface. Some of the bitter pitch is also gotten rid of in this manner.

The next step in the handling of this low-grade gum is to steam it. The steaming apparatus consists of a wooden box 4 feet square and 1 foot deep, fitted over a large funnel 4 feet square at the top and tapering to a narrow neck at the bottom. Between the (Concluded on page 671)

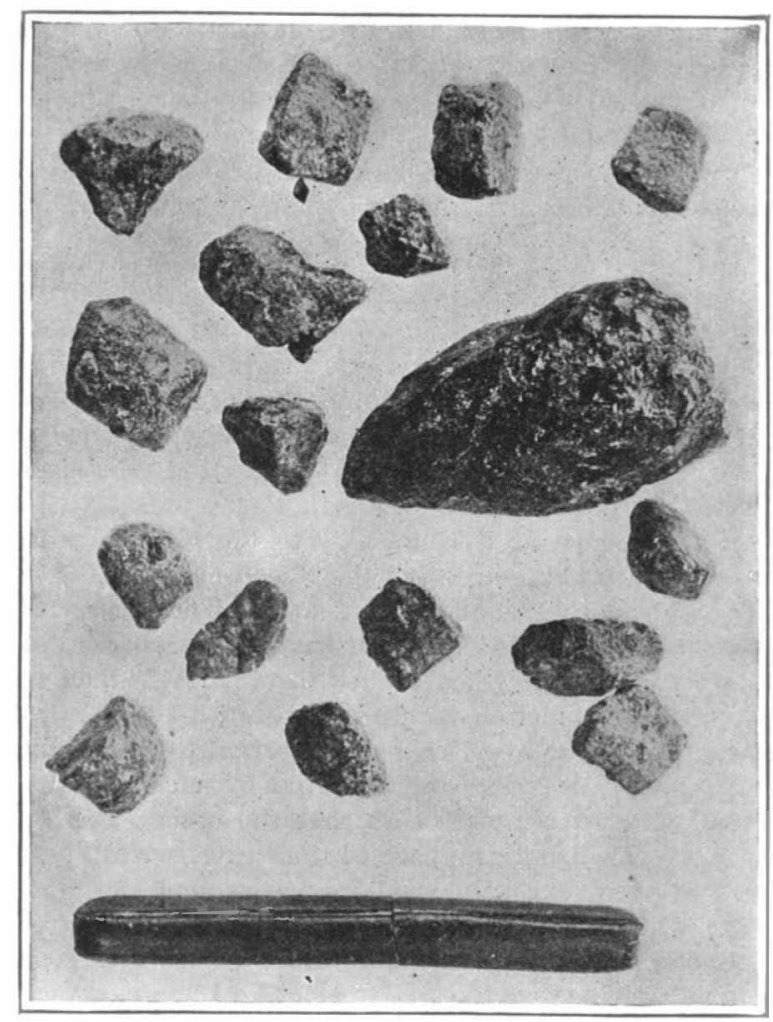

Spruce gum nuggets and a piece of steamed oum in stick form 
LEGAL NOTICES

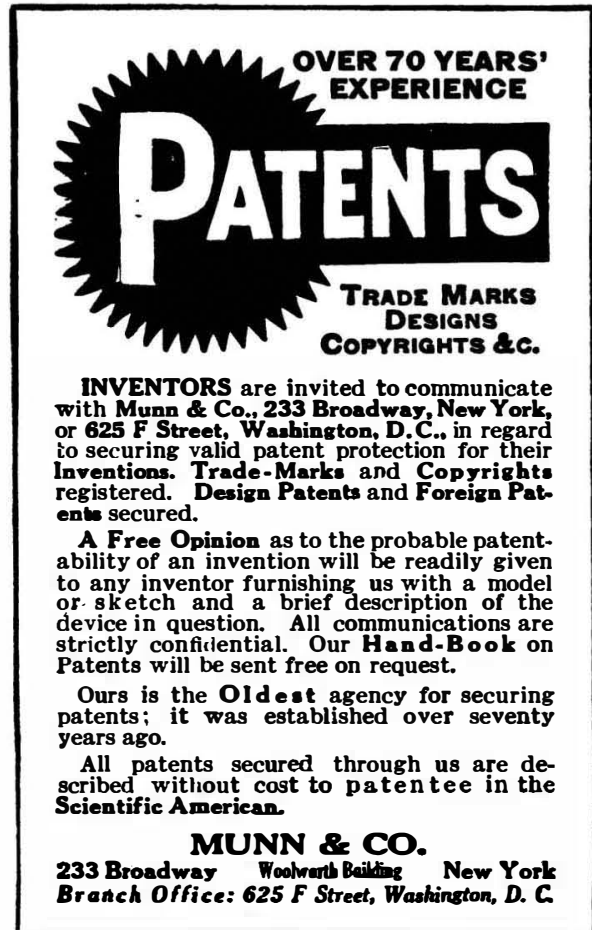

Annual Subscription Rates for the Scientific American Publications

Subscription one vear. 23.00

Postage prepaid in United States and possessions
Mexico, Cuba and Panama.

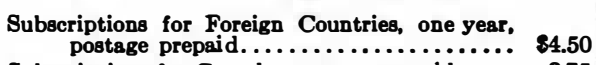
Subscriptions for Canada, postage prepaid .... 3.75
The Scientific American Publications Scientific American (established 1845)......... 83.00

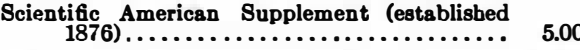
The combined subscription rates and rates to forei
countries, including Canada, will be furnished
upon application.

Remit by postal or express money order, bank
draft or check.

Classified Advertisements

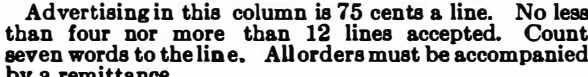
BUIDD GRANDFATHER'S CLOCKS

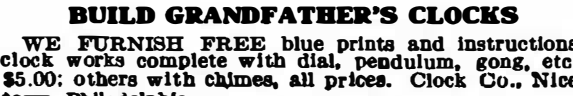
BUSINESS OPPOCTUNT: WORTH WHILE TO PARTY who can handle. Want
capltial to patent Beveral lnventlons. One completed and
geveral nearly o. Capltal to handle all money. E. B POR SALE

WE HAYE a Dumber of embossdng Outaw which sell
for 250 each, complete, including overything to do the

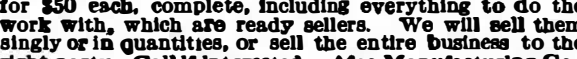
tyght party. Call 11 Intereested. Afco Manubac
71-73 Naseav Street, New York City.

WGET METAR STAMPING

. SITUATIONS WANTED YODNG INVENTOR SEEKS ENGAGEMENT
Dealrea no pay whatever until ablilty has been thoroughty Box 773. New Yor

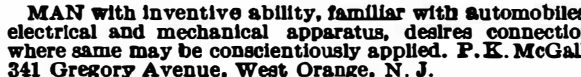

NOVELTIES \& PATENTED ARTICLES

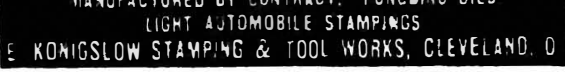

MASON'S NEW PAT. WHIIP HOIST tor Outrigger holsts. Faster than Elevatora. and holst Manufactured by VOLNEY W. MASON \& CO.. Ine
Providence. R. I.. U. S. A.

HOTEL BALDWIN BEACH HAVEN, $\mathbf{N}$. J.

Directly on the ocean, with unobstructed
view of Sea or Bay from all rooms. The view of Sea or Bay from all rooms. The
ideal modern hotel of the most attractive and delightful resort along the New Jersey coast. Open all year. Capacity for 400 appointment with the highest degree of comfort. Sea water in all baths, telephones porches surround the hotel. NEW WISTARIA GARDEN AND GRILL; music, dancing, frequent social features; tea dan-
sants. Tennis and outdoor sports; finest fishing, sailing and bathing. Garage. Table supplied direct from nearby farms and dairies. Literature, auto maps and terms upon request. Reached via C. R. R. of N. J. Magnificent Auto Boulevard fron New York
The Spruce Gum Industry Concluded from page 660 )

bottom of the box and the funnel is stretched the cheese cloth, while the top is covered with burlap upon which the chip gum is spread in a thin layer. an through the burlap. The gum melts and runs through the burlap and cheese cloth strainers and into a tin receptacle below the mouth of the funnel.

While the gum is still warm it is taken out of the receptacle and worked or pulled. This makes it more uniform in density and lightens the color. It is next laid on a bench and rolled flat with heavy rollers, the last one having heavy dies cut into it to separate the gum into small sticks or squares. These are wrapped in tissue paper and sell in the retail market for about one cent apiece.

Some makers adulterate their steamed gum by introducing rosin. Others mix it with chicle. One formula for the latter calls for 20 parts each of spruce gum and hicle and 60 parts powdered sugar. The gums are melted separately, mixed while hot, and the sugar immediately added, a small portion at a time, and kneaded in on a hot slab. When the sugar is completely incorporated the mass is removed to a cold slab, previously dusted with sugar, rolled out at once into sheets and cut into sticks.

The true lover of spruce gum is not attracted by such hybrids. His test of good gum is first in the taste and then in the color. When the lump is first crushed in the mouth there should be an agreeable bitterness, but no trace of turpentine. The particles should soon adhere together in proper consistency, turn to a light lavender shade, and retain the characteristic flavor indefinitely.

\section{A Model Hospital Train}

(Continued from page 664)

nickel, and all other parts are white enameled. The walls and ceilings of the sterilizing compartment are white varnished, and in their lower portions are covered with a varnished cloth that is readily washed.

bide the sterilizing roment is situated all medicaments and provisions in two spacious cupboards. In another compartment of the car there have been installed X-ray outfits, enabling the wounded to be rapidly inspected before being operated upon. The apparatus is also used in inspecting plaster dressings. The induction coil of the X-ray apparatus receives its primary energy from the trainlighting circuit, and the bulb is readily adjusted along the radioscopic table.

Since the possibility of conveying soldiers suffering from infectious diseases had to be accounted for, a special disinfection car has been included in the hospital train. This car is fitted with every possible facility to reduce the risk of inpection to a minimum. The disinfector is designed for disinfecting the body and bed linen of patients, their mattresses, pillows, etc., in a stream of live steam at a temperature of 108 to 110 degrees. In order to enable even clothes, leather and apparatus has been designed for formaline disinfection. Furthermore, with a view to destroying vermin, so dangerous in time of war, physical disinfection with carbonic acid and hot air has likewise been provided for. A steam washing machine insures a preliminary cleaning of blood-stained and dirty linen. Steam for this machine and the disinfector is supplied from a steam boiler installed in the car. Two spacious receptacles lined with sheet metal serve to store dirty linen not infected and disinfected linen, respectively. In a cabinet there is a shower bath for the doctors and the attendants. The lighting car is in reality a power plant on wheels, and supplies electrica illumination to all the cars. The latter are equipped with compressed gas apparatus to be resorted to in case of emergency. Electricity is generated by a generator direct-coupled to a 12-horsepowe four-cylinder gasoline motor. The load

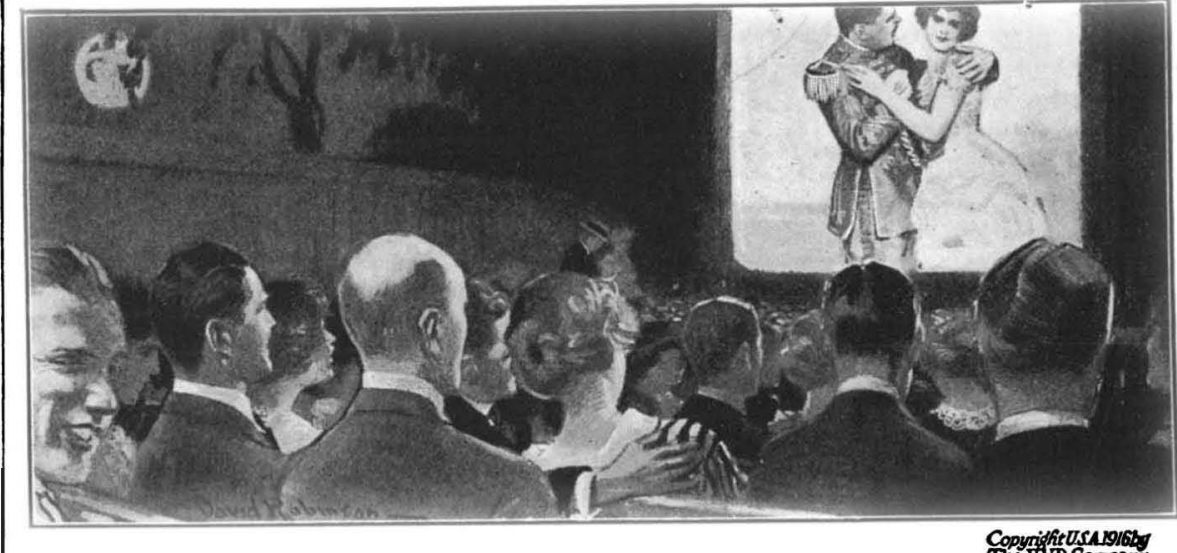

\section{Night or Day, at Work or Play B.V.D. Conserves Your Comfort}

NOTHING is so typical of the American "level head," as the nation-wide popularity of B.V.D. It is the Summer Underwear of Efficiencyof the man who conserves his comfort at work or at play, just as he conserves his health-as an asset.

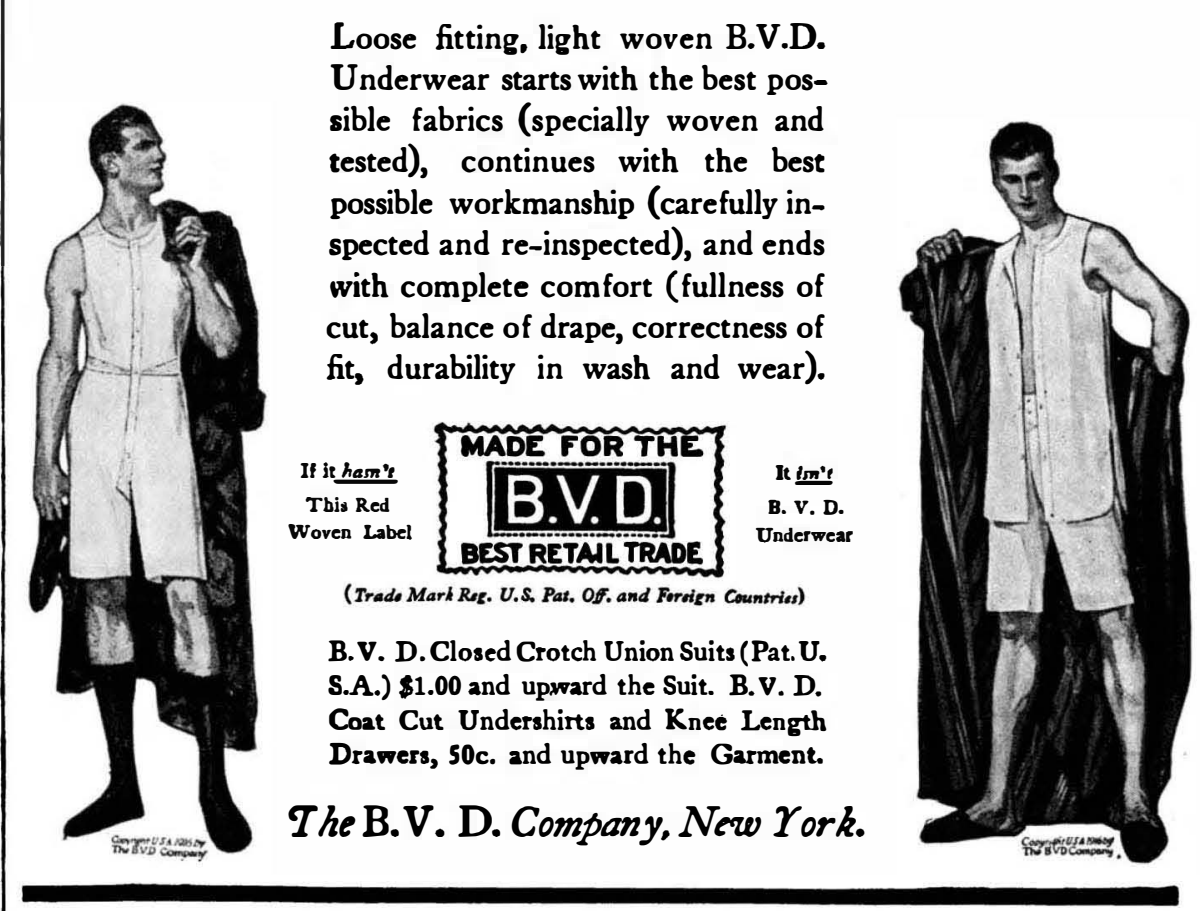

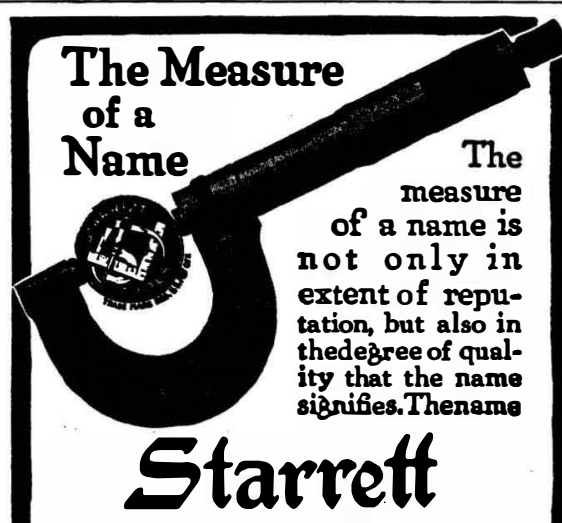

Means Awoys and Everywher Tools and lnstruments of Writo for New Catalog No. 21-B, just is rules, squares. levels, calipers micrometers.
gabes hack saws and many others. THE L. S. STARRETT CO. "The World's Greatest Tool
Makers"
ATHOL, MASS.
Londono Now York, Chiceso Makers'
LTHOL, MASS.
Londono Now York, Chicaso

Valuable Books of Instructionand Reference

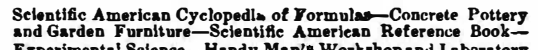
MUNN \& CO., lac., Pablishers, Wootworth Eut.o New Pork

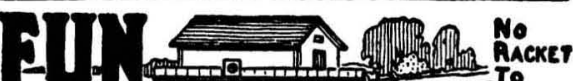
Manor Gamo At Home-Camp or Club Raise your score of hits Then toach the whol
family-women and all-to protoct themselves in
case of need. Besides it's great sport Use a case of need Besides it's great sport Use a

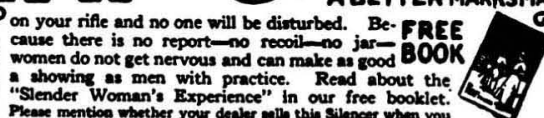

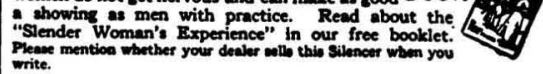

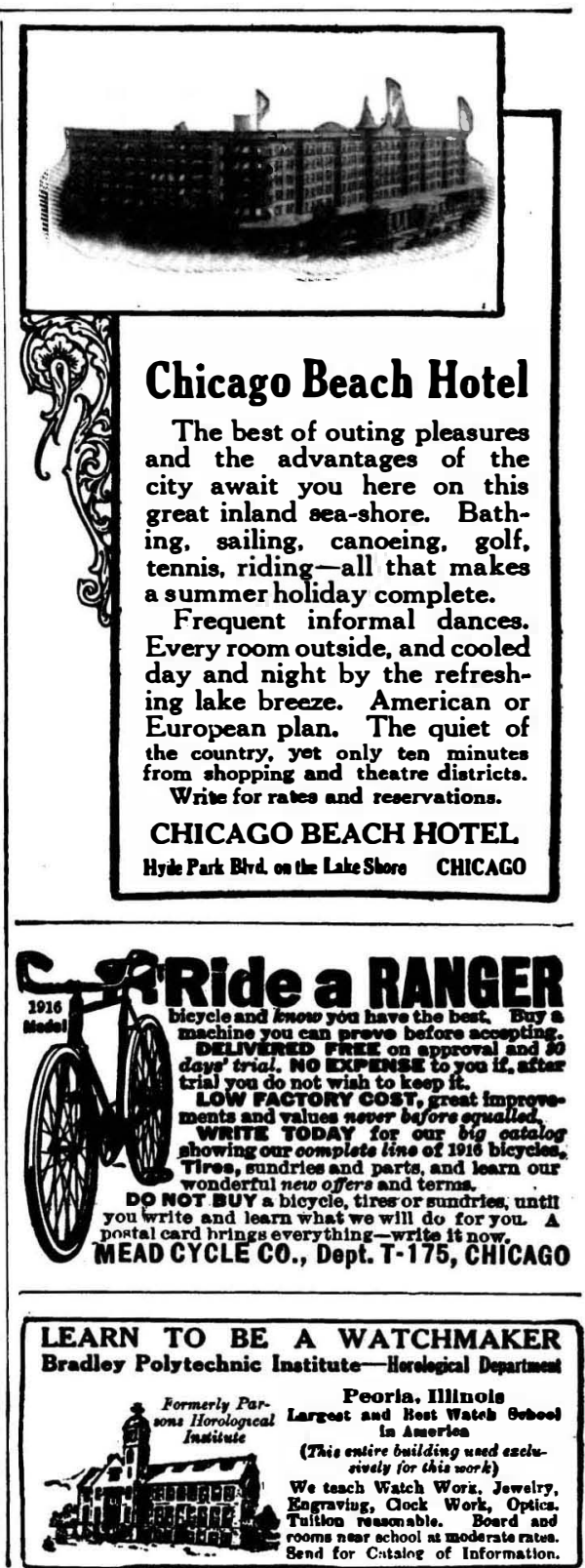




\section{Railroad Fire-Fighting Apparatus Used} in Canada $\mathrm{A}_{\text {ible to say so, it is nevertheless the }}^{\text {LTHOUGH it seems almost incred- }}$ truth that the railroads of this country are powerless to combat their own fires with effective fire-fighting apparatus. The underwriter's list shows a huge loss annually to the railroads where fires oc curred in sections removed from city fire protection. If the city firemen can not respond or the city fireboats can not help fight the fire, the railroad sits idly by and waits until the blaze dies out.

Not a day goes by but what one reads in newspaper accounts of fires where engines pulled away freight cars from the danger zone. But one never reads of engines helping extinguish a blaze. There is no such thing as a fire-fighting locomotive, nor a fir ghting railroad carthat is, if one excludes the apparatus which forms the basis for this article. From the standpoint of efficiency and preparedness our railroads might be classed with the extreme pacifists of peace at any price.

When it became evident last year to the directors of the Transcontinental Railway of Canada that something had to be dono, and done quick, too, in regard to the loss along the right-of-way by fires, an order for a fire-fighting car was turned over to the Canadian Government Railways' Shops at Moncton, New Brunswick. Shortly thereafter an apparatus consisting of a large water tank of more than 10,000 gallons capacity, mounted on a flat car in order that it mas be transferred to any point on the system be transferred to any point on the system
where fire may be threatening, was put in operation. It has already paid for itself many times over, although it is perhap the only car of its kind in existence.

Mounted on the tank is a steam drive pump having a capacity of 300 gallons a minute. This pump is supplied with al necessary hose, nozzles and other fittings. The steam supply for operating it is taken from the car heater of the locomotive to which the car may be attached, and by setting the car heater regulator of the locomotive at a pressure of 125 pounds to the square inch a water pressure of about 100 pounds is obtained at the nozzle

Before the Transcontinental Railway accepted the apparatus it was tested an found to be capable of throwing two oneinch streams of water a distance of about 200 feet to either side of the track. Two or three men can operate the nozzles and one man the pump, although two men in an emergency can work the apparatus to its full capacity. American railroad men are watching the car with interest. It will not be long before our railroads will have an efficient flre-fighting equipment of their own, if the flre car in Canada proves successful.

\section{Applying Truck Tires With a Press}

THE accompanying illustration shows how one company re-tires truck wheels in a minimum of time, saving expense and loss of time to the firm that needs every truck to maintain its prompt service delivery.

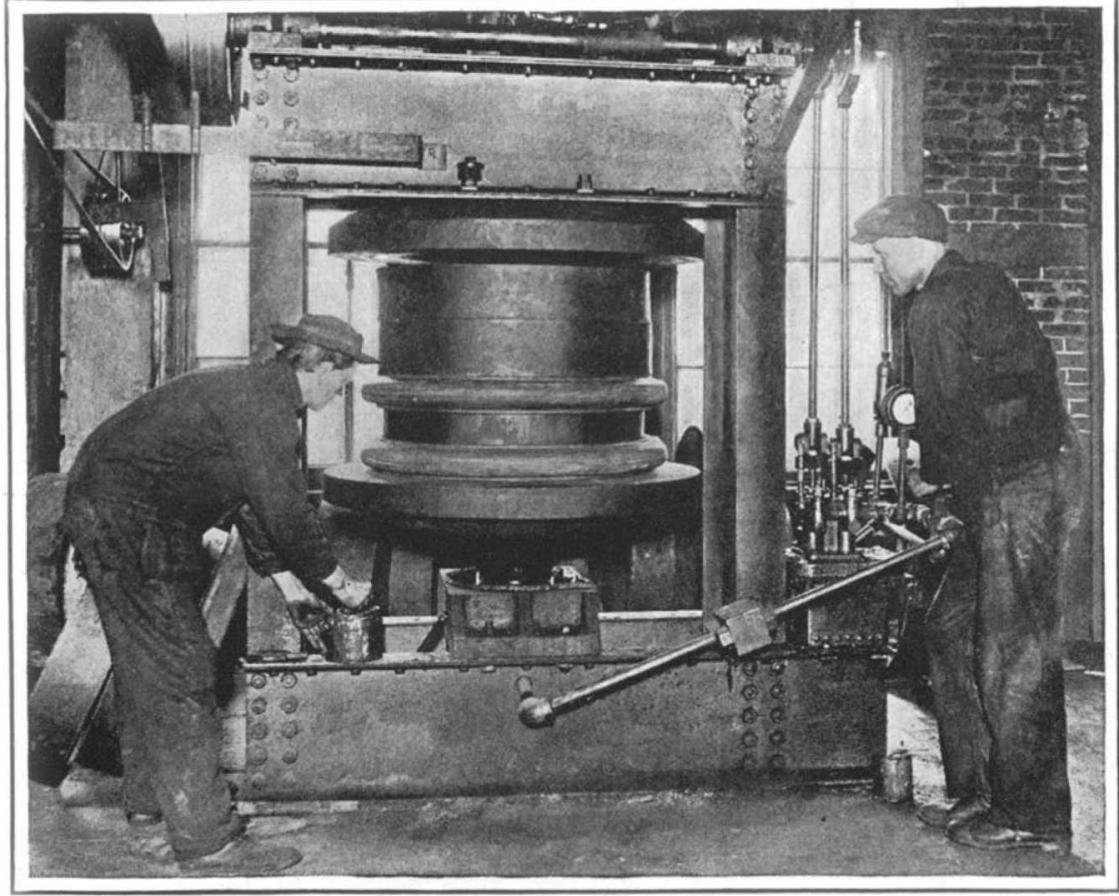

A typical hydraulic press in the act of pressing dual solid tires into position on a motor-truck wheel
The wheel needing a new tire is placed in a hydraulic press. With steel cylinders acting as buffers, the old tire is pressed off under 100 tons pressure, to be rebuil or discarded. A steel band for the felloe, if such is needed, is taken care of by appliances on hand. A band heater, fed with natural gas, prepares it for the wheet,

(1)
to an posich it is placed. It is much lighter back carried pre from the face the tunnel by one or two men can be done in a few minutes' time, whereas with a tin duct each joint would have to be disconnected and carried back and the operation repeated after the blast able time. If a hole is punched in the tubing, it can be easily patched or a . section of any length-desired can be inserted in a few minutes. With fans of suitable capacity, it is possible to deliver air for distances varying from 500 to 600 feet with ease. When the fans are not working the tubing collapses and can be hung on, or pushed against, the side of the tunnel. When the fans are started the tubing fills out and remains so as if it were reinforced with a spiral of steel wire.

It is particularly in the ventilation of mines without cross-cuts that the canvas tubing is attracting much attention. Heretofore it has been the practice to force a great volume of air through the shafts and entries of a mine, dividing or splitting the current at different points in its course so as to carry it to every part of the mine. Usually the galleries or tunuels are driven in pairs, and at frequent intervals connecting-tunnels or cross-cuts are driven between them so as better to circulate the flow of air. As the work in each gallery progresses

and cold water quickly shrinks it immovably into place. Replaced on the hydraulic press, the wheel receives its new tire under necessary pressure, steel cylinders again acting as buffers. The entire operation requires but a comparatively short time.

In the accompanying illustration is shown how dual solid tires are forced into position on a truck wheel, in a few moments' time and the face advances farther and farther, the crossin order that the air current will not find a ready bypath and thus fail to reach the head of each gallery in any appreciable volume. By means of the canvas duct it is believed that successful ventilation of mines can be carried on without the use of frequent crosscuts.

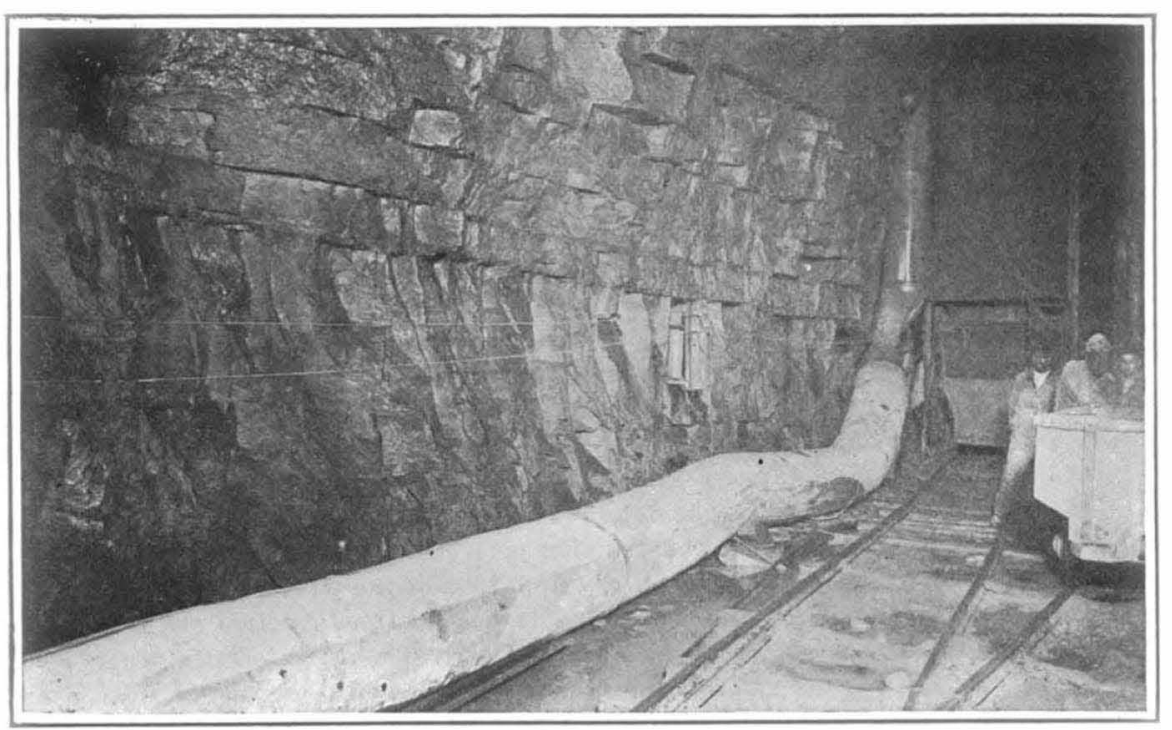

Canvas air duct in a mine, at the point where it connects with a metal tube leading to the fan

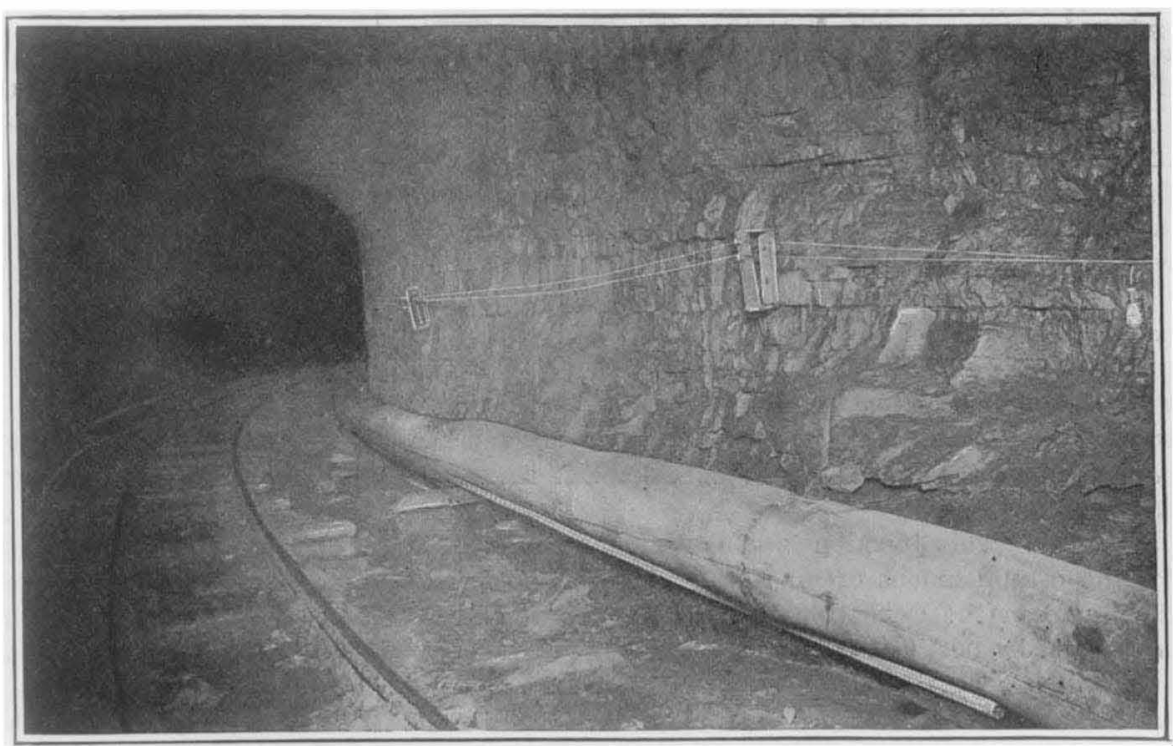

Installation of a canvas air duct in a mine. Note how it adspts itself to floor irregularities 